\title{
Implementasi Sistem Penunjang Keputusan Menggunakan Business Intelligence Untuk UMKM Di Gunung Putri Kab. Bogor
}

\author{
Ade Priyatna \\ Program Studi Sistem Informasi, STMIK Nusa Mandiri \\ Jl. Damai No. 8 Warung Jati Barat (Margasatwa) Jakarta Selatan
}

\begin{abstract}
ABSTRAKSI
Ketersedian data dan informasi menjadi hal yang penting dalam proses pengambilan keputusan sebagai bahan analisa perkembangan UMKM atau organisasi, kebutuhan data dan informasi yang lengkap benar dan tepat juga menjadi kebutuhan bagi kelangsungan perkembangan UMKM ke depan. Sistem penunjang keputusan menggunakan business intelligence ini menggunakan tool pengolahan dari microsoft yaitu sql server integration services (SSIS) dan sql server reporting services (SSRS). Business Intelligenci juga dapat membantu sebuah UMKM atau organisasi untuk mendapatkan pengetahuan yang jelas mengenai faktor-faktor yang mempengaruhi kinerja organisasi sehingga dapat membantu organisasi dalam pengambilan keputusan serta sekaligus meningkatkan keunggulannya (competitive advantage). Business Intelligenci juga dapat membantu suatu organisasi dalam menganalisis perubahan tren yang terjadi sehingga akan membantu organisasi menentukan strategi yang diperlukan dalam mengantisipasi perubahan tren tersebut. penelitian ini bertujuan untuk memberikan hasil dashboard atau report yang nantinya akan digunakan sebagai bahan pengambilan keputusan. penelitian ini dilakukan pada UMKM di Gunung Putri Kab. Bogor. sumber data diperoleh dari sistem lama atau dari user kemudian diolah dengan sistem baru. hasil antara report sistem baru dan sistem lama kemudian dibandingkan menggunakan software spss untuk melihat presentase perbedaan nilainya.
\end{abstract}

Kata kunci: Sistem, Penunjang Keputusan,Sql,UMKM, Business Intelligence, Software

\section{ABSTRACT}

The availability of data and information becomes an important thing in the decision-making process as an analysis of the development of MSMEs or organizations, the need for complete and correct data and information is also a necessity for the continued development of MSMEs in the future. Decision support system uses business intelligence using Microsoft processing tools, sql server integration services (SSIS) and sql server reporting services (SSRS). Business Intelligence can also help an MSME or organization to gain clear knowledge about the factors that affect organizational performance so that it can assist organizations in making decisions and at the same time improve their competitive advantage. Business Intelligence can also help an organization to analyze changes in trends that occur so that it will help organizations determine the strategies needed to anticipate changes in these trends. this study aims to provide dashboard results or reports that will later be used as material for decision making. this research was conducted on MSMEs in Gunung Putri Kab. Bogor. data sources are obtained from the old system or from the user then processed with the new system. the results between the new system report and the old system are then compared using the spss software to see the percentage difference in value.

Keywords: System, Decision Support, Sql, UMKM, Business Intelligence, Software

\section{PENDAHULUAN}

Perkembangan teknologi informasi yang di integrasikan dengan proses pekerjaan menjadi kebutuhan yang harus dilakukan oleh sebuah organisasi. Hal tersebut dilakukan untuk meningkatkan kemampuan dalam menganalisis masalah yang dihadapi oleh organisasi serta juga untuk proses pengambilan keputusan oleh manajemen. Business Intelligence System merupakan istilah yang umumnya digunakan

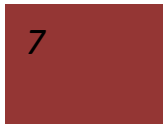


untuk jenis aplikasi ataupun teknologi yang digunakan untuk membantu kegiatan, seperti mengumpulkan data, menyediakan akses, serta menganalisa data dan informasi mengenai kinerja dari sebuah organisasi. Business Intelligence merupakan seperangkat teori, metodologi, proses, arsitektur, dan teknologi yang mengubah data mentah menjadi informasi yang bermakna dan berguna untuk tujuan bisnis. BI dapat menangani sejumlah besar informasi untuk membantu mengidentifikasi dan mengembangkan peluang baru. Memanfaatkan peluang baru dan menerapkan strategi yang efektif dapat memberikan keuntungan pasar kompetitif dan stabilitas jangka panjang (Vercellis,Carlo., 2009).

\section{TINJAUAN PUSTAKA}

\subsection{Business Intelligence}

Business Intelligence (BI) merupakan sistem dan aplikasi yang berfungsi untuk mengubah data-data dalam suatu perusahaan atau organisasi (data operasional, data transaksional, atau data lainnya) ke dalam bentuk pengetahuan.Aplikasi ini melakukan analisis data-data di masa lampau, menganalisisnya dan kemudian menggunakan pengetahuan tersebut untuk mendukung keputusan dan perencanaan organisasi.Business Intelligence memiliki arti sebagai kumpulan dan serangkaian kegiatan atau tahapan untuk mengumpulkan data dan menganalisis data sehingga dapat digunakan untuk proses pengambilan keputusan yang lebih baik sehingga dapat digunakan dalam proses pengambilan keputusan vital dalam bisnis perusahaan atau keputusan untuk memperoleh tujuan dari bisnis perusahaan (taufiqurrochman et al., 2017).

Busines Inteligence juga dapat membantu sebuah perusahaan atau organisasi untuk mendapatkan pengetahuan yang jelas mengenai faktor-faktor yang mempengaruhi kinerja organisasi sehingga dapat membantu organisasi dalam pengambilan keputusan serta sekaligus meningkatkan keunggulannya (competitive advantage). Busines Inteligensi juga dapat membantu suatu organisasi dalam menganalisis perubahan tren yang terjadi sehingga akan membantu organisasi menentukan strategi yang diperlukan dalam mengantisipasi perubahan tren tersebut. BI dapat diartikan sebagai pengetahuan yang didapatkan dari hasil analisis data yang diperoleh dari kegiatan suatu organisasi (siswono.,2013).

\subsection{UMKM}

Menurut Undang Undang Nomor 20 Tahun 2008 tentang Usaha Mikro, Kecil dan Menengah (UMKM). Disana disebutkan, usaha mikro adalah usaha produktif milik orang perorangan dan atau milik bada usaha perorangan yang memenuhi kriteria usaha mikro sebagaimana diatur dalam Undang undang ini. Kriteria UMKM adalah usaha yang maksimal assetnya Rp. 50 juta dan omsetnya maksimal Rp. 300 juta

\subsection{Tools Pengolahan Microsoft}

A. SQL Server Integration Services (SSIS)

$S Q L$ Server Integration Services ( SSIS ) adalah komponen perangkat lunak basis data Microsoft SQL Server yang dapat digunakan untuk melakukan berbagai tugas migrasi data.SSIS merupakan platform untuk integrasi data dan aplikasi alur kerja. Ini merupakan fitur alat pergudangan data yang digunakan untuk ekstraksi data , transformasi, dan pemuatan (ETL) . Alat ini juga dapat digunakan untuk mengotomatiskan pemeliharaan database SQL Server dan pembaruan data kubus multidimensi.

\section{B. SQL Server Reporting Service (SSRS)}

SQL Server Reporting Services ( SSRS ) adalah sistem perangkat lunak pembuat laporan berbasis server dari Microsoft. Ini adalah bagian dari rangkaian layanan Microsoft SQL Server, termasuk SSAS ( SQL Server Analysis Services ) dan SSIS ( SQL Server Integration Services ).

Dikelola melalui antarmuka Web, dapat digunakan untuk menyiapkan dan menyampaikan berbagai laporan interaktif dan cetak. Layanan SSRS menyediakan antarmuka ke Microsoft Visual Studio sehingga pengembang serta administrator SQL dapat terhubung ke database SQL dan menggunakan alat SSRS untuk memformat laporan SQL dengan berbagai cara yang kompleks. Ini juga menyediakan alat 'Pembuat Laporan' untuk

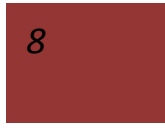


pengguna yang kurang teknis untuk memformat laporan SQL dengan kompleksitas yang lebih rendah.

Sumber: wwww.microsoft.com

\subsection{Pengambilan Keputusan}

Pengambilan keputusan secara universal didefinisikan sebagai pemilihan diantara berbagai alternative. Pengertian ini mencakup baik pembuatan pilihan maupun pemecahan masalah. Pengambilan keputusan yang rasional sangat diperlukan bagi setiap organisassi dimana para manajel dituntut melakukan suatu tindakan yang lebih rasional dalam menghadapi setiap masalah yang ada. Pengambilan keputusan rasional adalah suatu proses sistematik di mana manajer menetapkan masalah, mengevaluasi alternatif, dan memilih pemecahan optimal untuk memberikan manfaat yang maksimal kepada organisasi (Modul Pengantar manajemen, Drs. Al Mashar, MM. 2015).

\section{METODOLOGI}

Dalam penelitian ini dilakukan empat tahap aktifitas utama yakni:

\section{Tahap Observasi}

Tahap pertama yang dilakukan adalah perencanaan, yang akan dimulai dengan menyiapkan tools/software apa saja yang dibutuhkan dalam pembuatan aplikasi ini dan dilakukan penelitian dengan metode wawancara untuk mengetahui kebutuhan para pengguna aplikasi.

\section{Studi Kepustakaan}

Membahas permasalahan yang ada pada pengembangan layanan aplikasi ini, diperlukan buku-buku dan artikel dari internet yang berhubungan dengan business intelligence.

\section{Tahap Pengolahan Data}

Data yang didapat dari observasi kemudian mengukur kesalahan perspektif yang menghasilkan pertanyaan dan akan dilakukan analisa.

\section{Pengujian dan Implementasi}

Setelah pembahasan business intelligence selesai, kemudian melakukan pengujian atau tes case pada system kemudian dan melakukan penerapan pada system.

\section{HASIL DAN PEMBAHASAN}

\subsection{Arsitektur Sistem Lama}

Pada system lama ada perantara admin yang bias mengakses database dan kemudian admin memberikan laporan dalam bentuk excel kepada user.

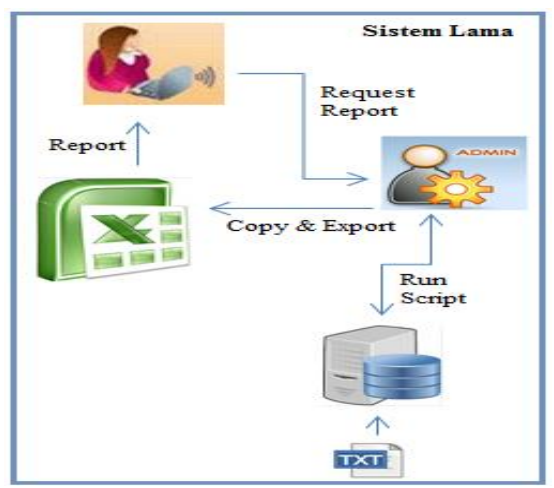

Sumber : Hasil Penelitian (2018)

Gambar.1 Sistem Lama

Proses dimulai ketika user meminta laporan kepada admin, proses berlanjut admin melakukan run script ke database system kemudian hasil dari query script di copy oleh admin ke dalam excel, kemudian diteruskan kembali kepada user. Pada system ini user hanya memperoleh report dalam bentuk excel serta user harus mencari terlebih dahulu lapaoran yang dibutuhkan dari excel tersebut.

\subsection{Arsitektur System Baru}

Pada system baru user bias langsung mengakses laporan yang bersumber dari database, tampilan report yang menarik serta kemudahan informasi bisa langsung diakses user tanpa perantara

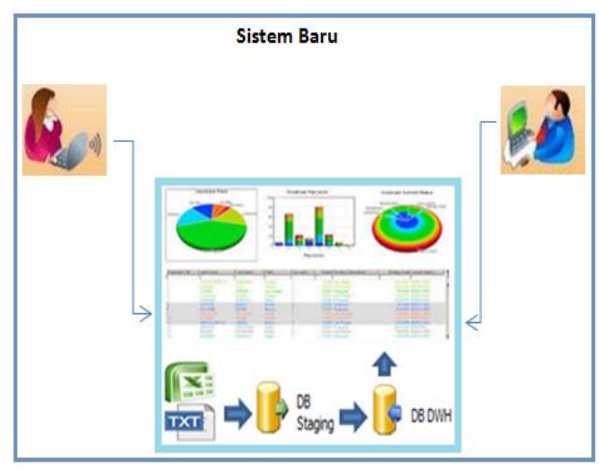

Sumber : Hasil Penelitian (2018)

Gambar 2. Sistem Baru

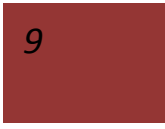


Proses dimulai dari penarikan data Extract ,Transfer, Load (ETL) dari source text file dan excel masuk kedalam database Staging, setelah itu proses penarikan data berlanjut masuk sampai Database Dwh. Pada saat user mengakses report maka akan tampil laporan-laporan terbaru sesuai dengan informasi yang ingin dilihat oleh user. Tampilan laporan yang di hasilkan lebih menarik dan mudah dipahami oleh user serta user bias dengan mudah mencari informasi yang dibutuhkan

\section{A. Business Intelligence (BI)}

Sahu,Rajesh Kumar (2012) mengatakan bahwa Business Intelligence (BI) adalah seperangkat teori, metodologi, proses, arsitektur, dan teknologi yang mengubah data mentah menjadi informasi yang bermakna dan berguna untuk tujuan bisnis. BI dapat menangani sejumlah besar informasi untuk membantu mengidentifikasi dan mengembangkan peluang baru. Memanfaatkan peluang baru dan menerapkan strategi yang efektif dapat memberikan keuntungan pasar kompetitif dan stabilitas jangka panjang

\subsection{Pengujian Sistem}

\begin{tabular}{llr}
\multicolumn{1}{c}{ Proses pengujian data dilakukan } \\
menggunakan program SPS & yaitu \\
pembandingkan data dari system yang lama \\
dengan data dari hasil aplikasi BI.
\end{tabular}

\section{A. Tahapan Pengujian}

Ada beberapa langkah proses pengujian sistem yang harus dilakukan diantaranya adalah sebagai berikut :

a. Memastikan source text file sudah ada dilokasi sesuai folder path

b. Memastikan table Etl_Source_Target sudah ada untuk package yang akan dijalankan

c. Menjalankan bath file untuk proses running Staging

d. Menjalankan bath file untuk proses running Dimension

e. Menjalankan bath file untuk proses running fact table

f. Menjalankan prosese deploy untuk proses Report SSRS

g. Mengakses link akses report BI

h. Melakukan import Data ke dalam Excel
Setelah proses data di Extract ke dalam Excel kemudian dilakukan proses perbandingan data dari system lama dan data dari hasil pengolahan Busines Inteligence.

\section{B. Proses Perbandingan Data}

Data hasil dari pengolahan Bussiness Intelligence akan dibandingkan dengan data yang berasal dari system lama dengan system BI. Dari hasil perbandingan menggunakan SPSS metode descriptives diperoleh hasil sebagai berikut :

a. Report Inventory

- Analisa perbandingan Name Item berdasarkan tahun

Tabel 1. Hasil Perbandingan Report Inventory Tahun 2009

\begin{tabular}{|c|c|c|c|c|}
\hline \multicolumn{3}{|c|}{ Tahun } & Statistic & Std. Error \\
\hline \multirow[t]{13}{*}{2009} & Mean & & 28.5000 & 2.17945 \\
\hline & \multirow{2}{*}{$\begin{array}{l}95 \% \text { Confidence Interval } \\
\text { for Mean }\end{array}$} & Lower Bound & 24.1323 & \\
\hline & & Upper Bound & 32.8677 & \\
\hline & $5 \%$ Trimmed Mean & & 28.5000 & \\
\hline & Median & & 28.5000 & \\
\hline & Variance & & 266.000 & \\
\hline & Std. Deviation & & 16.30951 & \\
\hline & Minimum & & 1.00 & \\
\hline & Maximum & & 56.00 & \\
\hline & Range & & 55.00 & \\
\hline & Interquartile Range & & 28.50 & \\
\hline & Skewness & & .000 & .319 \\
\hline & Kurtosis & & -1.200 & .628 \\
\hline
\end{tabular}

Sumber : Hasil Penelitian (2009)

Tabel 2. Hasil Perbandingan Report Inventory Tahun 2010

\begin{tabular}{|c|c|c|c|c|}
\hline \multirow[t]{13}{*}{2010} & \multicolumn{2}{|l|}{ Mean } & 28.5000 & 2.17945 \\
\hline & \multirow{2}{*}{$\begin{array}{l}95 \% \text { Confidence Interval } \\
\text { for Mean }\end{array}$} & Lower Bound & 24.1323 & \\
\hline & & Upper Bound & 32.8677 & \\
\hline & \multicolumn{2}{|l|}{$5 \%$ Trimmed Mean } & 28.5000 & \\
\hline & \multicolumn{2}{|l|}{ Median } & 28.5000 & \\
\hline & \multicolumn{2}{|l|}{ Variance } & 266.000 & \\
\hline & \multicolumn{2}{|l|}{ Std. Deviation } & 16.30951 & \\
\hline & \multicolumn{2}{|l|}{ Minimum } & 1.00 & \\
\hline & \multicolumn{2}{|l|}{ Maximum } & 56.00 & \\
\hline & \multicolumn{2}{|l|}{ Range } & 55.00 & \\
\hline & \multicolumn{2}{|l|}{ Interquartile Range } & 28.50 & \\
\hline & \multicolumn{2}{|l|}{ Skewness } & .000 & .319 \\
\hline & \multicolumn{2}{|l|}{ Kurtosis } & -1.200 & .628 \\
\hline 2011 & \multicolumn{2}{|l|}{ Mean } & 28.5000 & 2.17945 \\
\hline
\end{tabular}


Tabel 3. Hasil Perbandingan Report Inventory

Tahun 2011

\begin{tabular}{|l|r|r|}
\hline 2011 & 28.5000 & 2.17945 \\
\cline { 2 - 4 } $\begin{array}{lr}\text { Mean } \\
\text { for Mean }\end{array}$ & 24.1323 & \\
\hline 5\% Trimmed Mean & 32.8677 & \\
\hline Median & 28.5000 & \\
\hline Variance & 28.5000 & \\
\hline Std. Deviation & 266.000 & \\
Minimum & 16.30951 & \\
\cline { 2 - 4 } Maximum & 1.00 & \\
\hline Range & 56.00 & \\
\hline Interquartile Range & 55.00 & \\
\hline Skewness & 28.50 & \\
\hline Kurtosis & .000 & .319 \\
\hline
\end{tabular}

Sumber : Hasil Penelitian (2011)

b. Report Sales

- Analisa perbandingan

Tabel 4. Hasil Perbandingan Report Sales SlpName Erwin

\begin{tabular}{|c|c|c|c|c|}
\hline \multicolumn{3}{|l|}{ SlpName } & \multirow{2}{*}{\begin{tabular}{|r|} 
Statistic \\
2.0000
\end{tabular}} & \multirow{2}{*}{$\begin{array}{r}\text { Std. Error } \\
.57735\end{array}$} \\
\hline \multirow[t]{13}{*}{ Erwin } & Mean & & & \\
\hline & $95 \%$ Confidence Interval for Mean & Lower Bound & .4841 & \\
\hline & & Upper Bound & 4.4841 & \\
\hline & $5 \%$ Trimmed Mean & & & \\
\hline & Median & & 2.0000 & \\
\hline & Variance & & 1.000 & \\
\hline & Std. Deviation & & 1.00000 & \\
\hline & Minimum & & 1.00 & \\
\hline & Maximum & & 3.00 & \\
\hline & Range & & 2.00 & \\
\hline & Interquartile Range & & & \\
\hline & Skewness & & .000 & 1.225 \\
\hline & Kuntosis & & & \\
\hline
\end{tabular}

Sumber : Hasil Penelitian (2018)

Tabel 5.

Hasil Perbandingan Report Sales SlpName

\begin{tabular}{|c|c|c|c|c|}
\hline \multirow[t]{13}{*}{ Kantor (Utensil/Kantor) } & \multicolumn{2}{|l|}{ Mean } & 2.0000 & .57735 \\
\hline & \multirow[t]{2}{*}{$95 \%$ Confidence Interval for Mean } & Lower Bound & -.4841 & \\
\hline & & Upper Bound & 4.4841 & \\
\hline & \multicolumn{2}{|l|}{ 5\% Trimmed Mean } & & \\
\hline & \multicolumn{2}{|l|}{ Median } & 2.0000 & \\
\hline & \multicolumn{2}{|l|}{ Variance } & 1.000 & \\
\hline & \multicolumn{2}{|l|}{ Std. Deviation } & 1.00000 & \\
\hline & \multicolumn{2}{|l|}{ Minimum } & 1.00 & \\
\hline & \multicolumn{2}{|l|}{ Maximum } & 3.00 & \\
\hline & \multicolumn{2}{|l|}{ Range } & 2.00 & \\
\hline & \multicolumn{2}{|l|}{ Interquartile Range } & & \\
\hline & \multicolumn{2}{|l|}{ Skewness } & .000 & 1.225 \\
\hline & \multicolumn{2}{|l|}{ Kurtosis } & & \\
\hline
\end{tabular}

Sumber : Hasil Penelitian (2018)

4.3 Tampilan Sistem \& Implementasi Sistem

\section{A. Tampilan Sistem}

Dalam proses pelaporan SSRS (Sql Server Reporting Services) menampilkan 3 Report, yaitu Report inventory, Sales Report - by Salesman dan Sales Report - by warehouse

a. Report inventory

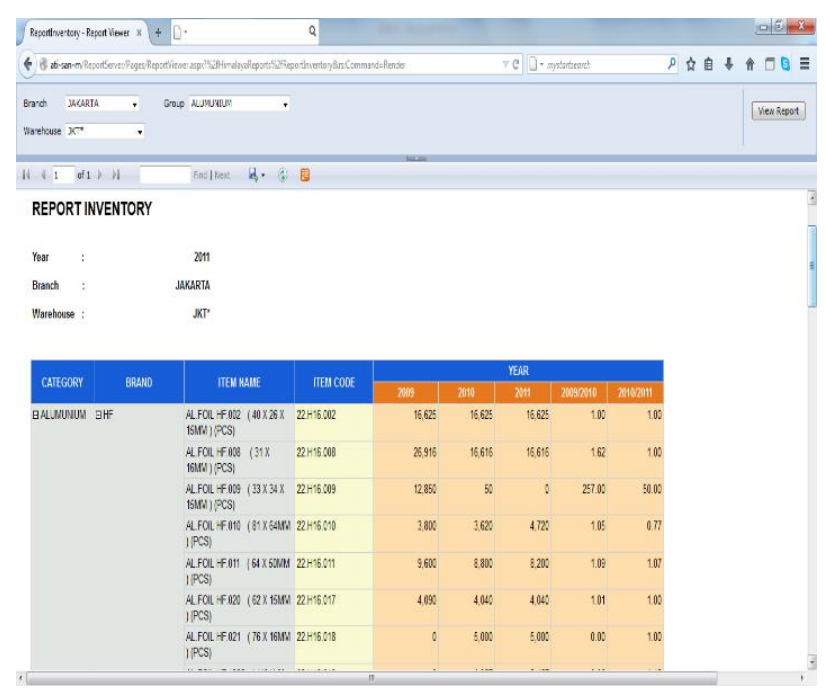

Sumber : Hasil Penelitian (2018)

Gambar 3. Report Inventory

Pada report inventory terdapat filter branch, warehouse dan grouping berdasarkan productnya.

b. Sales Report - by Salesman

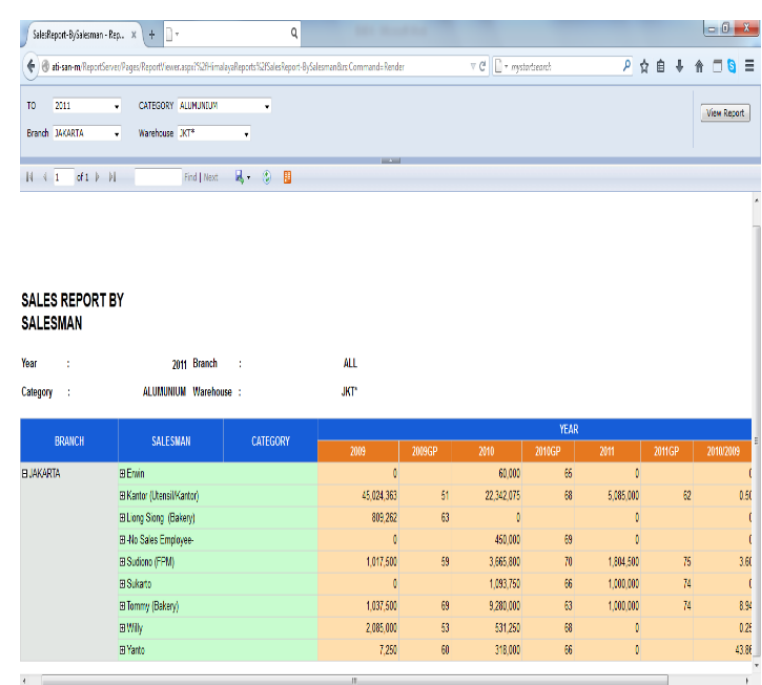

Sumber : Hasil Penelitian (2018)

Gambar 4. Sales Report by Salesman 
Pada Sales Report by Salesman terdapat filter diantaranya Tahun, branch, Category Product, dan lokasi warehouse.

c. Sales Report - by warehouse

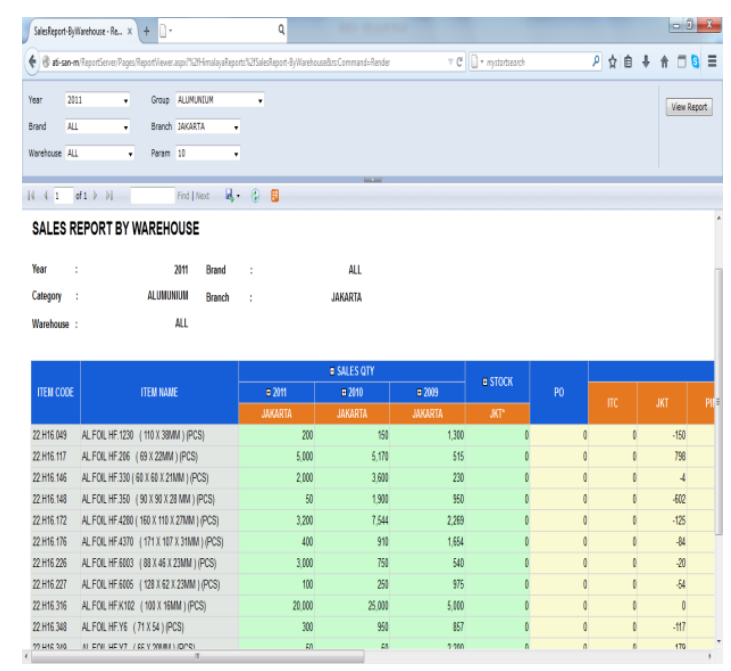

Sumber : Hasil Penelitian (2018)

\section{Gambar 5. Sales Report - by warehouse}

Pada Sales Report - by warehouse terdapat beberapa filter diantaranya filter tahun, Category, warehouse, brand dan branch.

\section{B. Implementasi Sistem}

Setelah semua proses pengujian berhasil dilakukan, kemudian akan dilakukan proses penggunaan langsung oleh user ke dalam server production.

\section{KESIMPULAN DAN SARAN}

Dari hasil penelitian tentang pengolahan data menggunakan Bussiness Intelligence diperoleh hasil untuk masing-masing analisa report yang terdiri dari

\subsection{Kesimpulan}

a. Report Inventory

Hasil pengolahan data dari aplikasi lama dan aplikasi baru sama yaitu dengan rata mean sebesar 6137,4821 dengan nilai minimal yang sama yaitu 0 dan nilai maksimal sebesar 135.000 .

\section{b. Report Sales}

Hasil pengolahan data dari aplikasi lama dan aplikasi baru sedikit berbeda hasilnya ini dikarenakan ada perbedaan nilai angka dibelakang koma atau proses rounding. Nilai mean dari pengolahan data dari aplikasi lama atau user sebesar 3578194,409 sedangkan nilai mean dari aplikasi baru sebesar 3578194,444. Nilai minimal sama yaitu 0 dan nilai maksimal dari aplikasi lama sebesar 45024362,50 sedangkan aplikasi baru sebesar 45024363,00 .

c. Report Warehouse

Hasil pengolahan data dari aplikasi lama dan aplikasi baru berbeda hal ini dikarenakan ada beberapa nilai dari item code yang belum masuk ke dalam aplikasi baru.

\subsection{Saran}

Untuk UMKM pengadaan barang dan jasa, hasil penelitian ini dapat dijadikan acuan dalam pengambilan keputusan dari hasil report yang ditampilkan UMKM akan mendapatkan informasi untuk kemajuan UMKM dan dapat meningkatkan pemanfaatan untuk proses analisa kebutuhan data UMKM.

Untuk pengembangan penelitian selanjurtnya disarankan untuk menggunakan Bussiness Intelligence dengan menggunakan share point untuk proses analisa dan pemanfaatan informasi yang lebih luas serta adanya pengembangan report tidak hanya report inventory, report sales dan report warehouse tetapi dapat mengembangkan untuk Report atau laporan yang lain sesuai kebutuhan UMKM.

\section{REEFERENSI}

Siswono.(2013).PERAN

BUSINESS INTELLIGENCE DALAM SOLUSI BISNIS.Comtech Vol. 4 No.2.Binus University.813 Sahu, Rajesh Kumar. (2012)."Business Intelligence for Banking" India: Ifosys Finacle.

Taufiqurrochman.Eko Indrajit Ricahardus . dan Muh Fauzi., (2017). Seminar Nasional Sains dan Teknologi.Fakultas Teknik.Universitas Muhamadiyah akarta.2 Vercellis, Carlo. (2009), "Business Intelligence : Data Mining and Optimization for Decision Making". United Kingdom: John Willey and Sons, Ltd. www.microsoft.com 